\title{
Finding indications of lag time, saturation and trading inflow in the emergence record of exotic agricultural insect pests in Japan
}

\author{
Nobuo Morimoto $^{1} \cdot$ Keizi Kiritani $^{2} \cdot$ Kohji Yamamura ${ }^{3} \cdot$ Takehiko Yamanaka $^{3,4} \mathbb{D}$
}

Received: 7 May 2019 / Accepted: 19 August 2019 / Published online: 20 September 2019

(c) The Author(s) 2019

\begin{abstract}
Agricultural imports are the primary pathway for the introduction of exotic insect pests. The invasion records of exotic insect pests are also influenced by the lag time before detection and saturation caused by the limited species pool of potential invaders. We compiled an exhaustive list of exotic insect species in mainland Japan and tried to evaluate the connection between the commodity types of agricultural imports and insect types of agricultural pests, in addition to the effects of lag time and saturation. We found that lag time was prominent when all pest types were merged into one group, whilst saturation always existed when we divided the records into the four agricultural pest types. Saturation was especially prominent in stored product pests because this group contained many cosmopolitan insect pests that could have easily inhabited the newly built mills throughout Japan in the 1950s. We suspect that the saturation effect was masked by admixture amongst pests with different saturation patterns. Our findings indicate that all commodities, i.e. flowers, fruits, vegetables, cereal and timber, contributed to the invasion of pest insects as potential pathways. However, it was unclear if certain items had comparatively greater significance in this process.
\end{abstract}

Keywords Exotic insects $\cdot$ Invasive pest $\cdot$ Trading imports $\cdot$ Pathway

\section{Introduction}

Many exotic insects have been causing serious agricultural damage for more than 100 years (Yamanaka et al. 2015). They often turn out to be a destructive agricultural pest in a new land because of their competitive life history traits against the other native pests and/or of escaping from their natural enemies or host defences in their homeland (Sakai

Electronic supplementary material The online version of this article (https://doi.org/10.1007/s13355-019-00640-2) contains supplementary material, which is available to authorized users.

Takehiko Yamanaka

apple@affrc.go.jp

1 Institute of Livestock and Grassland Science, NARO, 2 Ikenodai, Tsukuba, Ibaraki 305-0901, Japan

2 1020-292 Futo, Itō, Shizuoka 413-0231, Japan

3 Institute for Agro-Environmental Sciences, NARO (NIAES), 3-1-3 Kannondai, Tsukuba, Ibaraki 305-8604, Japan

4 Research Center for Agricultural Information Technology, NARO (RCAIT), Kintetsu Kasumigaseki Bld, Kasumigaseki 3-5-1, Chiyoda, Tokyo 100-0013, Japan et al. 2001). An earlier report indicated that more than half of the crop losses in the United States were caused by exotic insect pests (Sailer 1978). In Japan, 8.8\% of agricultural insect pest species are exotic (Yamanaka et al. 2015). Although the percentage in Japan is rather small as compared to that in the United States, the list of exotic insect species contains destructive agricultural ones, such as rice water weevil [Lissorhoptrus oryzophilus Kudo (Coleoptera: Curculionidae)], leafminers [Liriomyza trifolii (Burgess) (Diptera: Agromyzidae)] and several thrips [Frankliniella occidentalis (Pergande) (Thysanoptera: Thripidae), Megalurothrips distalis (Karny) (Thysanoptera: Thripidae) and Scirtothrips dorsalis Hood (Thysanoptera: Thripidae)]. The number of insecticidal applications drastically increased in Japan after 1970s as the inflow of exotic insect pests increased on agricultural farmlands (Kiritani 2004).

Trades, especially agricultural imports, are believed to be the primary pathway of exotic insect pests, whilst migration with military cargo, association with passenger luggage, intentional releases of useful or pet insects, or autonomous range expansions are also possible (Aukema et al. 2010; Chapman et al. 2017; Kiritani and Yamamura 2003). Chapman et al. (2017) found that the amount of 
agricultural imports was the most important driver of exotic pest inflow amongst the other socio-environmental factors in Europe. Kiritani and Yamamura (2003) also pointed out that more than $80 \%$ of exotic insects in Japan are suspected to have been introduced through agricultural products. The Plant Protection Act was implemented in 1914 in Japan because many nations of the world realised that the trading of agricultural products was the main pathway for the transfer of invasive species during that period (http://www.maff.go.jp/pps/j/guidance/pestinfo/pdf/pesti nfo_105_1-2.pdf).

There have been several attempts at modelling the correspondence between the trade volume and the accumulation of exotic species. Levine and D'Antonio (2003) modelled the relationship between the international trade and the cumulative numbers of invasions in the United States. They found that $\log -\log$ and $\log$-linear species-area models, as well as the Michaelis-Menten accumulation function, were suitable for modeling the relationship. Their results indicated that the invasion speed is slowing down with time. The invasion process cannot be simply modelled because although the events are proportional to the amount of imports, the number of invasions can be attenuated as they are gradually accumulated in the new lands (Costello et al. 2007; Levine and D'Antonio 2003). If a species pool of highly invasive organisms is finite, the invasion incidence will be depleted sooner or later as we cannot count them twice. Though Seebens et al. (2017) concluded that there were no signs of saturation in invasion records when all invasion records across the world were investigated, we may find such saturation in some exotic pest categories with some commodity classes in Japan.

In addition, it has been recognised that there is usually a lag time between the actual timing of invasion and the discovery (Kowarik 1995; Mack et al. 2000; Sakai et al. 2001). New exotic species require time to grow their population size and expand their habitats so that they can be found by investigators. Kiritani and Yamamura (2003) picked up 35 invasion incidences of exotic insects in Japan, in which the timing of actual invasion could be somehow estimated and found that the lag time between actual invasion and discovery was 11.8 years on average and was 3.8 years on average when pests with extremely long latent periods were excluded.

In our study, we tried to evaluate all the factors described above in the invasion records of exotic insect pests in Japan, i.e. lag time, saturation and trading inflow. Our analyses are basically based on the methodology of Costello et al. (2007). To see the relative importance amongst the factors, a recently developed criterion $R_{\mathrm{D}}$, which is a measurement of predictability, is estimated for all the models of various combinations of agricultural commodities, with the lag time and saturation effect (Yamamura 2016).

\section{Methods}

\section{Data collection}

A list of exotic insect species in mainland Japan was compiled based on the previous work (Yamanaka et al. 2015). Only species considered as established in mainland Japan (excluding Okinawa and Ogasawara islands) were incorporated into our analysis, whilst transiently detected and successfully eradicated species were not included. We further estimated the first year of detection of each exotic insect by referring to any reliable information source, e.g. scientific journal papers, national and regional governmental reports, environmental survey records available on the internet, national library collections, and so on. All the records and their references are summarised in one spreadsheet and are available in the Electronic Supplementary Material.

The exotic insects in our spreadsheet were divided into agricultural pests and others. The agricultural pests were further categorised into five pest types: Outdoor pests, Stored pests, Greenhouse pests, Forest pests and Timber pests (Table 1; Fig. 1). The classification procedure was based on the Japanese agricultural pest list of Major Insect and Other Pests of Economic Plants in Japan (The Japanese Society of Applied Entomology and Zoology 2006). Depending on if the exotic insects in our dataset were listed on the Japanese agricultural pest list, they were judged as agricultural pests or not and were also classified into the five pest types according to the information in the previous reports and/or internet resources. The results of the pest classification and their references can be found in the Electronic Supplementary Material.

Those categorised as Outdoor pests are the pests which feed on fruits, crops and vegetables in open fields. Some of them overlapped with Greenhouse pests and were tagged to both. Stored pests typically appear in ship cargoes and crop storages. Most of them are direct feeders on stored products, but some frugivorous and detritivorous insects were also included since they potentially degrade the quality of products [e.g. Latridiidae (Coleoptera), Carcinops pumilio (Histeridae: Coleoptera) and Ahasverus advena (Silvanidae: Coleoptera)]. Greenhouse pests are those typically observed in greenhouses. Because greenhouses became popular in the 1960s, pests categorised as Greenhouse pests may not always have a direct connection to greenhouses. If pests categorised as Greenhouse pests were also reported as pests in open fields, they were also tagged as Outdoor pests. Forest pests infest living trees. Some longicorn and leaf beetles [e.g. Ceresium sinicum (Signoret) (Coleoptera: Cerambycidae), Prosoplus bankii (Fabricius) (Coleoptera: Cerambycidae)] were included in 
this category in addition to lepidopteran pests of fruits trees [e.g. Grapholita molesta (Busck) (Lepidoptera: Tortricidae), Spilonota lechriaspis (Meyrick) (Lepidoptera: Tortricidae)]. The insects recognised as wood borers and timber pests were categorised as Timber pests whilst wood borers which only feed on living trees, were classified as Forest pests. It should be noted that termites were classified as Timber pests in our analyses.

There are 491 species listed as exotic insects excluding the domestic species spreading from Okinawa or Ogasawara. A total of 235 species out of 491 have records of the first year of detection after 1951, during which the importation records were available (see next paragraph). Furthermore, 165 species out of 235 species are recognised as agricultural pests falling into the five categories described above. We used both groupings (all 235 exotic species as one group and species categorised into five agricultural pest types) in our analyses.

The trading data can be found in the national statistics of trade in Japan (Ministry of Finance 1951-2016). We only used the data from 1951 since it was difficult to quantify the exact amount of imports before 1951. There were trading sanctions and embargo periods during and after World War II, and the commodity groups in older records were not compatible to the contemporary ones.

We specifically picked up five commodity groups; flowers, fruits, vegs, cereals, and timbers, amongst all the import records (Table 2), as we suspected that these could be the major pathways for the exotic agricultural pests. The flowers commodity is related to living flowers, recorded in metric tonnes. Though the other living plant materials, such as bulbs or nursery trees, could have been classified in the same commodity group, we eliminated them from our analyses. The nursery trees are highly correlated with flowers $(R=0.984)$. The number of bulbs imported was far smaller than those of flowers. The fruits and vegs are edible fruits and vegetables, excluding dried and frozen ones, and are recorded in metric tonnes. They can be a potential pathway of Outdoor crop pests, Greenhouse pests, and Tree and forest pests. The cereals commodity, both milled and unmilled, is also recorded in metric tonnes. Bean imports, including soybeans and peanuts, were also included in cereals. Though beans could have been treated separately from cereals in our analyses, the temporal trends between cereals and beans were strongly correlated $(R=0.977)$. Therefore, they were treated in the same category so that we could reduce the number of predictors in our analyses. The cereals commodity may have a strong connection to Stored pests. The timbers commodity comprises wood material (excluding furniture, thin sliced boards, charcoals, corks and chips) and is recorded in cubic metres. The amount of timber import may have some correspondence to Timber pests. 
(a) Total

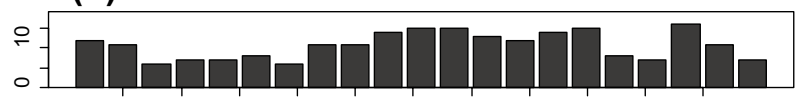

(b) Coleoptera

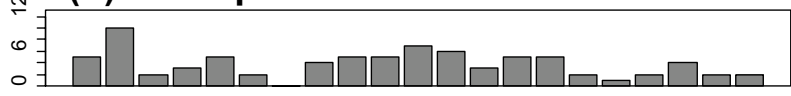

(c) Hemiptera

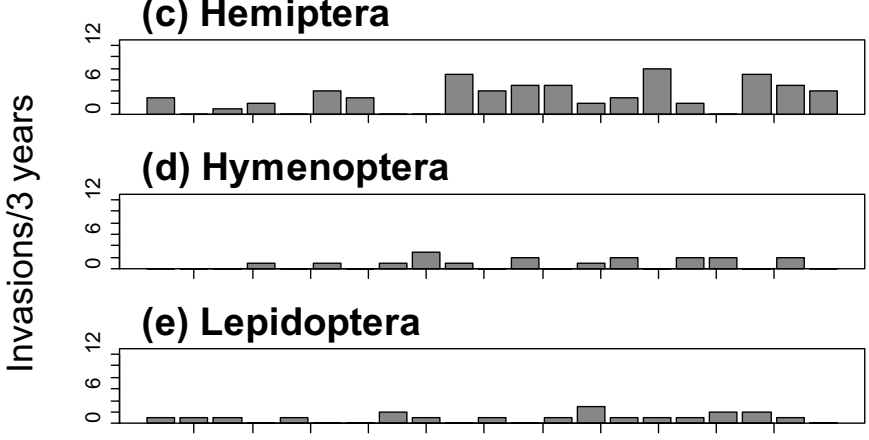

(f) Diptera

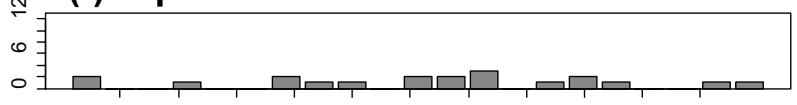

(g) Others

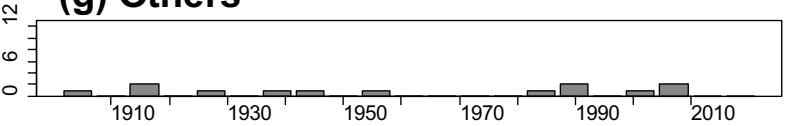

(h) Outdoor pests

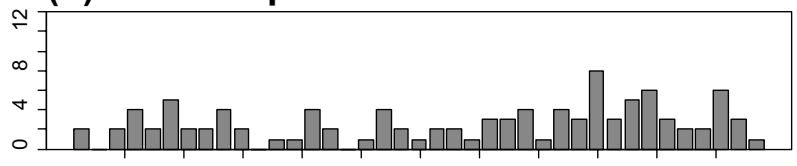

(i) Stored pests

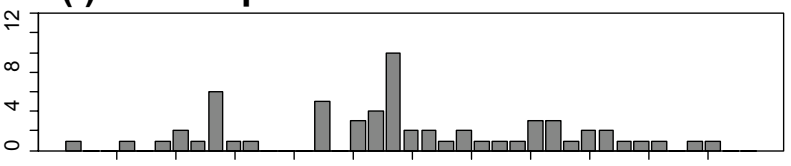

(j) Greenhouse pests

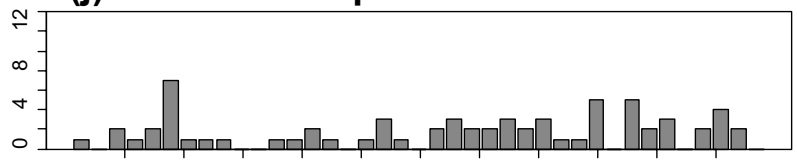

(k) Forest pests

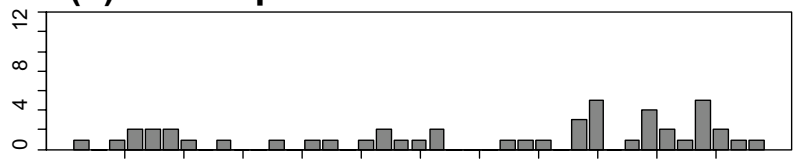

(I) Timber pests

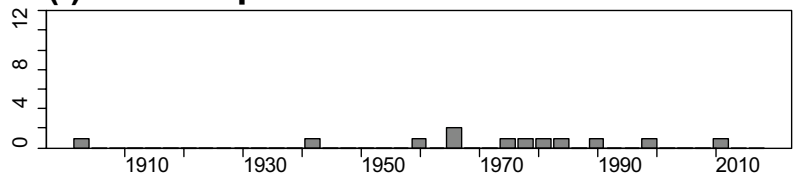

Year first found

Fig. 1 Temporal trends in exotic insect discoveries. a Total number of emergences. The records are also summarised in taxonomic order (a-g) and in order of agricultural pest type (h-l, see text for detail). The records are aggregated every 3 years after 1900 for visibility

Table 2 Trading commodities

\begin{tabular}{llll}
\hline Commodity & Explanation & HS-code $^{\mathrm{a}}$ & Commodity code $^{\mathrm{b}}$ \\
\hline Flowers & Living flowers & Chapter 6 (0603 and 0604 only) & $292-6,292-7$ \\
Fruits & Fruits (excluding dried and frozen ones) & Chapter 8 (0801-9) & 051,052 \\
Vegs & Vegetables (excluding dried and frozen ones) & Chapter 7 (0701-7, 0709, 0714) & $054-1-8,055-1$ \\
Cereals & Cereals (unmilled) & Chapter 10 & $041,042,043,044,045$, \\
& Cereals (milled) & Chapter 11 & $047,048-1,048-2$, \\
& Beans & Chapter 7 (0708 and 0713 only) & $055-4$ \\
Timbers & Timbers (excluding furniture, thin sliced boards, & Chapter 12 (1201 and 1202 only) & 244 \\
& charcoals, corks, and chips) & & \\
\hline
\end{tabular}

${ }^{\text {a }}$ The commodity was classified according to the standard HS code (Ministry of Finance 1976-2018)

${ }^{\mathrm{b}}$ The commodity was classified according to the Japanese classification scheme (Ministry of Finance 1951-1975)

Basically, all five commodity groups exhibited increasing tendencies until recently; however, the timber import clearly decreased after the 1990s (Fig. 2). The imports of flowers and vegs drastically increased after the 1990s and have a high correlation $(R=0.910)$. However, a small amount of vegs were imported even before the 1960s, whereas flowers were not. The fruits and cereals commodities are also highly correlated $(R=0.932)$; however, a substantial amount of cereal imports was observed even in the 1950s whilst the import of fruits suddenly increased around the 1970s during a period of high economic growth in Japan. 
Fig. 2 Temporal changes in the imports classified by commodity (a) flower

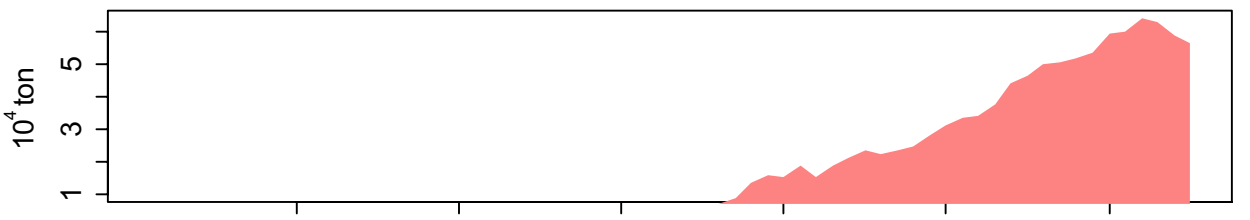

(b) fruits

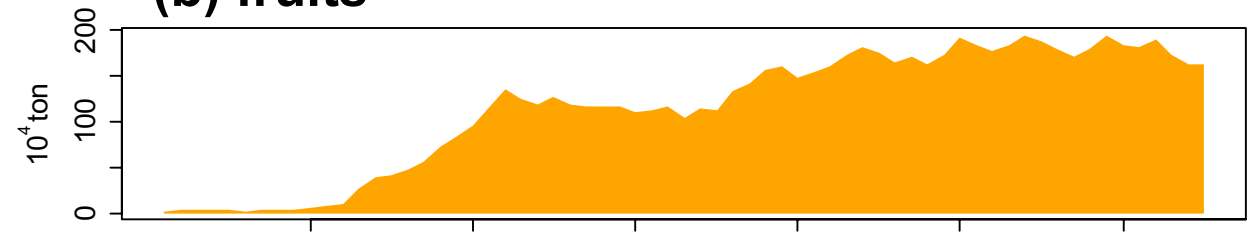

(c) veg

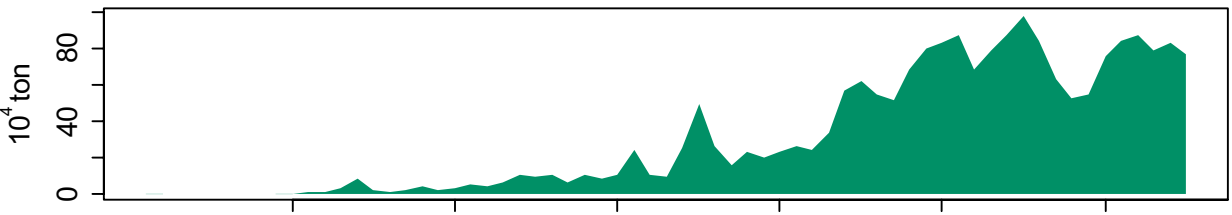

(d) cereal

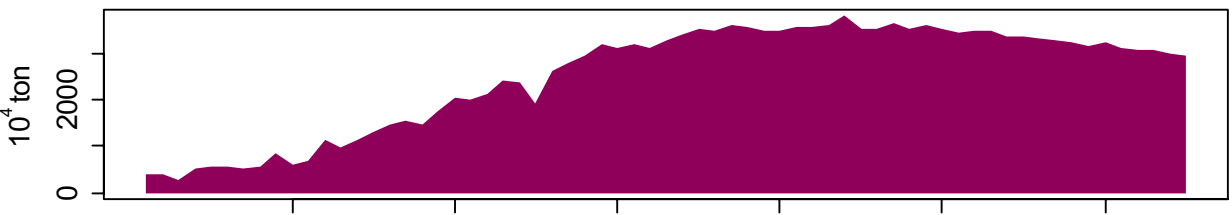

(e) timber

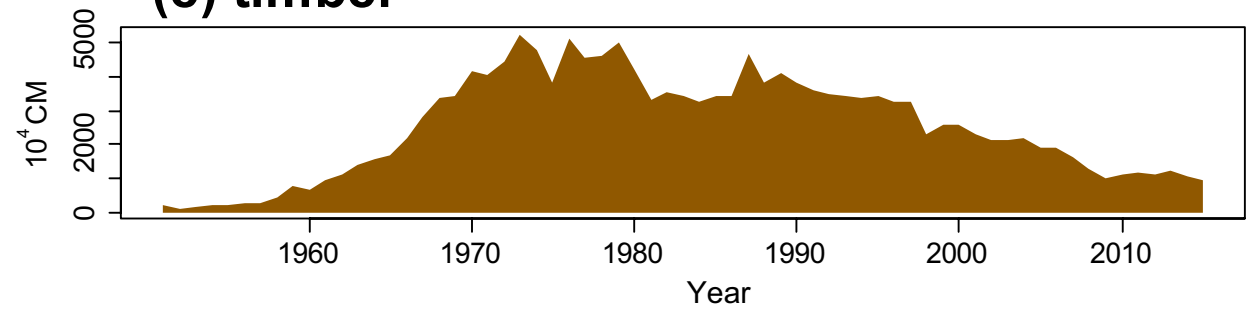

\section{Model structure}

Our model structure was based on Costello et al. (2007). Though they conducted the analyses based both on each regional trading and on the source regions of invasive species, we did not consider the source regions for both imports and exotic species. However, we did consider the commodity group and their corresponding exotic insects rather than the source region. It was partly because the source regions of many exotic insects in our list were unclear or difficult to identify. In addition, we suspected that some insects invaded into a different region and immigrated into Japan afterwards, especially the cosmopolitan pest insects (Garnas et al. 2016). In such cases, it would be hard to tell the direct source of the invasions. Therefore, we ignored the difference of the source regions and focussed our analyses from the viewpoint of commodity differences.
In addition to the five categories of the exotic and agricultural insect pests, we also conducted analyses for all the exotic insects in Japan with an estimated first year of detection to see the general trend without our arbitrary classification.

We started from a very simple model of the constant risk of invasions (Model-1) and then added the effect of commodity inflow (Model-2), the effect of saturation (Model-3) and the effect of lag time (Model-4) sequentially. Finally, the full model (Model-5), which has all the effects, was constructed. All five models were fitted individually to the number of invasion incidences of both the five pest types and all of them, i.e. all exotic insects.

We assumed an actual number of establishments of exotic insects at time $t$ as $Y_{t}$ and its expectation as $\lambda_{t}$, and formed a Poisson process model (Model-1)

$Y_{t} \sim \operatorname{Poisson}\left[\lambda_{t}=\exp (\beta)\right]$, 
where $\beta$ is a constant parameter. Then we added the effect of commodity inflow $\left(s_{i, t}: i \in 1,2, \ldots, m\right)$ at time $t . m$ is the total number of commodities ( $m=5$ in our case).

We named the model expressed by Eq. (2) as Model-2; it is the standard Poisson regression in the framework of the generalised linear model (Chambers and Hastie 1993):

$Y_{t} \sim \operatorname{Poisson}\left[\lambda_{t}=\exp \left(\beta_{0}+\beta_{1} s_{1, t}+\beta_{2} s_{2, t}+\cdots+\beta_{m} s_{m, t}\right)\right]$,

where $\beta_{i},\left(\beta_{i}>0\right)$ is the commodity-specific coefficients. All combinations $\left(\sum_{i=1}^{5} \operatorname{Combination}(5, i)=31\right)$ of the five commodity groups were tested in Model-2 and the other models hereafter.

The saturation was modelled by adding a negative component of the invasion accumulation until time $t\left(\sum_{j=1951}^{t-1} Y_{j}\right)$, which represents a decline in the probability of invasion over time:

$Y_{t} \sim$ Poisson $\left[\lambda_{t}=\exp \left(\beta_{0}+\sum_{i=1}^{m} \beta_{i} s_{i, t}-\gamma \sum_{j=1951}^{t-1} Y_{j}\right)\right]$,

where $\gamma(\gamma>0)$ is a constant parameter representing the saturation (Model-3). All combinations of the five commodity groups were also tested in Model-3.

Invading insects are not always discovered at the year of their establishment. In such cases, we should discriminate the number of exotic insects discovered at $t$ from the number of exotic insects established at $t$. Let $N_{t}$ be the number of exotic insects discovered at $t$. The quantity of $N_{t}$ may be much different from $Y_{t}$ that indicates the number of exotic insects established at $t$. Let us assume that an established insect is discovered by a fixed probability at each year. Then the expectation of $N_{t}$, which is denoted by $\delta_{t}$, is given by the summation of the products between the expectation of the actual establishment $\left(\lambda_{j}\right)$ and the probability of discovery $p_{j, t}$. The function $p_{j, t}$ is a geometric function of the probability of discovery per year $\pi(0<\pi<1)$. The quantity of $p_{j, t}$ can be interpreted as the product of probabilities between not being found until time $t-1\left((1-\pi)^{t-j}\right)$ and that being found at time $t(\pi)$. As there is little information related to the probability of discovery per year $\pi$, we just assumed that it is constant throughout the period of our analyses. Then the expected time until discovery will be $1 / \pi$.

$$
\begin{aligned}
& Y_{j} \sim \text { Poisson }\left[\lambda_{j}=\exp \left(\beta_{0}+\sum_{i=1}^{m} \beta_{i} s_{i, j}\right)\right] \\
& N_{t} \sim \operatorname{Poisson}\left(\delta_{t}=\sum_{j=1951}^{t} \lambda_{j} p_{j, t}\right) \\
& p_{j, t}=\pi(1-\pi)^{t-j} .
\end{aligned}
$$

Equation (4) represents Model-4, in which $t$ is the time of discoveries and $j$ is the time of actual invasions. A portion of species that was established before 1951 will be discovered after 1951. However, we ignore such species in Eq. (4) for convenience of estimation. Here, all combinations of the five commodity groups were also tested for Model-4.

Finally, the full model, which has all the effects of commodity inflow, saturation and lag time, was constructed. All combinations of the five commodity groups were also tested in Model-5.

$$
\begin{aligned}
& Y_{j} \sim \operatorname{Poisson}\left[\lambda_{j}=\exp \left(\beta_{0}+\sum_{i=1}^{m} \beta_{i} s_{i, j}-\gamma \sum_{k=1951}^{j-1} N_{k}\right)\right] \\
& N_{t} \sim \operatorname{Poisson}\left(\delta_{t}=\sum_{j=1951}^{t} \lambda_{j} p_{j, t}\right) \\
& p_{j, t}=\pi(1-\pi)^{t-j} .
\end{aligned}
$$

It should be noted that the saturation term in Model-5 was modelled by the accumulations of the number of detections $\left(N_{j}\right)$ rather than by the actual numbers of invasions $\left(Y_{j}\right)$, because $Y_{j}$ is not available from the data. We assumed that this discrepancy has a minimal effect on the parameter estimations because $N_{j}$ can be assumed to have a similar trend to that of $Y_{j}$.

\section{Parameter estimation}

All the models and analyses were conducted in the statistical environment $R$ (Version 3.2.3, CRAN; http://www.rproj ect.org, accessed in December 2018). The parameter estimation was executed by the optimization function optim in $R$-library. For the Poisson process model, the parameters were estimated with the data of actual establishments $\left(Y_{j}\right)$ by the maximum likelihood function of Eq. (6) for Eqs. (2) and (3):

$$
L(\beta, \gamma)=\prod_{j=1951}^{t} \frac{\exp \left(-\lambda_{j}\right) \lambda_{j}^{Y_{j}}}{Y_{j} !} \propto \prod_{j=1951}^{t} \exp \left(-\lambda_{j}\right) \lambda_{j}^{Y_{j}} .
$$

As $Y_{j}$ ! is a constant which can be solely calculated by the data and is independent of the parameters to be estimated, we simply needed to search the parameter sets which minimise the right part of Eq. (6). On the other hand, the parameter estimation for Eqs. (4) and (5) will be more complicated than that for Eq. (6).

$$
L(\beta, \gamma, \pi)=\prod_{j=1951+\tau}^{t} \frac{\exp \left(-\delta_{j}\right) \delta_{j}^{N_{j}}}{N_{j} !} \propto \prod_{j=1951+\tau}^{t} \exp \left(-\delta_{j}\right) \delta_{j}^{N_{j}} .
$$


The same invasion records used as $Y_{j}$ s in Eq. (6) were used as $N_{j}$ s in Eq. (7). However, $N_{j}$ is no longer the number of actual establishments but is the number of discoveries at time $t$. Notice that we are ignoring the species that entered before 1951 discovered after 1951 in Model-4 and 5. Hence, some biases may arise in the estimation. For an extreme example of $t=1951, \delta_{1951}$ is restricted to the number of discoveries of exotic insects that were established only in 1951 because this is when the dataset starts. For minimising such biases in the estimation, therefore, some 'preservation years $(\tau)$ ' are required before fitting the model for preventing $\delta_{t}$ from underestimation. That is, we should start the estimation process in Eq. (7) some time $(\tau)$ after 1951. If the expected time until discovery equals close to 1 year, i.e. $1 / \pi$ $\cong 1.0, \delta_{t}$ is identical to $\lambda_{t}$ in Eqs. (4) and (5). In such case, a few preservation years after 1951 will be enough to be excluded from the parameter estimation so that we can avoid the estimation bias for $\pi$. On the other hand, a substantial period should be preserved when $\pi \cong 0.0$; however, we will lose a lot of information regarding the imports and invasion events in the preserved period. Considering the precedent work of Kiritani and Yamamura (2003), who estimated the lag times as 3.8-11.8 years on average, we arbitrarily set up preservation periods $(\tau)$ as 5,7 and 11 years and compared them to $R_{\mathrm{D}}$ to decide which preservation periods should be employed (see next section for $R_{\mathrm{D}}$ ). After exhaustive optimization processes to fit the model to the data, $\tau=7$ gave the most predictive performance whilst those with $\tau=11$ also gave compatible predictions (results not shown). Therefore, we only used $\tau=7$ hereafter.

In addition, the parameter $\pi$ in the geometric function of Eqs. (4) and (5) is a so called "nuisance parameter", and it is well known that it is hard to be estimated in a standard maximum likelihood procedure using Eq. (7) (Berger et al. 1999). To avoid the problem, we first estimated $\hat{\beta}$ and $\hat{\gamma}$ by the marginalised likelihood function which can be obtained by integrating the Eq. (7) along all the plausible $\pi$ values: $I L(\beta, \gamma)=\int_{0}^{1}(\beta, \gamma, \pi) \mathrm{d} \pi$. Then we estimated $\pi$ using the likelihood function of $L(\hat{\beta}, \hat{\gamma}, \pi)$.

\section{Model predictability: $\boldsymbol{R}_{\mathrm{D}}$}

To compare the performances of multiple models, the Akaike information criterion (AIC) or related criteria are often employed (Burnham and Anderson 2014). The AIC families can be easily calculated and have a good balance between the goodness-of-fit and the simplicity to avoid overfittings. Though the AIC (Akaike 1974) has been considered as a popular index for such analyses, it has several drawbacks. Basically, the AIC and related methods for measuring the Kullback-Leibler divergence are dimensionless, i.e. they can only be used in the context of multi-model comparisons for a given amount of data and their exact values are meaningless. Therefore, we cannot compare the models with different subsets of the data. Also, they do not tell us whether we need more data to improve the model or not.

To tackle such problems, Yamamura (2016) recently proposed a new criterion, $R_{\mathrm{D}}$, which is a measurement of improvement in predictability. It can be calculated as the expected logarithmic probability of the target model given by the basic null model with the same data set. If the prediction is not different from the basic null model, $R_{\mathrm{D}}=0$. If we can perfectly predict the data with the target model, $R_{\mathrm{D}}=1.0$. It is calculated as follows:

$R_{\mathrm{D}}=1-\frac{D+2 k \hat{\phi}}{D_{\text {null }}+2 \hat{\phi}}=1-\frac{l_{\max }-l+k}{l_{\max }-l_{\text {null }}+1}$,

where $D$ and $D_{\text {null }}$ are the deviance of the target model and the null model, respectively. In our case, the null model in Eq. (8) is Model-1 of Eq. (1). $\hat{\phi}$ is the estimated dispersion parameter of the model and $k$ is the number of parameters of the model. Since $D=2 \phi\left(l_{\max }-l\right), D_{\text {null }}=2 \phi\left(l_{\max }-l_{\text {null }}\right)$ and $\phi$ should be 1.0 for the Poisson distribution, we can easily calculate $R_{\mathrm{D}}$ in the right side of Eq. (8) using the logarithmic probability of the target model $(l)$, that of the null model $\left(l_{\text {null }}\right)$ which only has a constant intercept parameter, and that of the full model $\left(l_{\max }\right)$ which is saturated with the exact same number of the parameters of fixed effects to the number of data. The calculation procedure of $R_{\mathrm{D}}$ is more complicated than that of AIC. Yamamura (2016) has provided some simple $R$ 3.4.1 (CRAN) and SAS 9.4 programming codes of the $R_{\mathrm{D}}$ calculation.

We tested 125 variants of the models with every combination of the commodity groups (Model-1: 1, Model-2 to Model-5: 31 for each) for the five exotic agricultural pest insects and all of them in one group. We calculated the $R_{\mathrm{D}}$ for each, compared them and selected the best five models above the null model (Model-1) so that we can evaluate the importance of the commodity groups and the effect of saturation and lag time in the invasion incidences of the exotic insect types.

\section{Results}

The results of all the exotic insects are shown in Fig. 3 and Table 3. The best model is Model-4 with the effect of cereals and timbers imports and lag time but without saturation (Fig. 3d). According to Yamamura (2016), it is a rule of thumb that only the models with $R_{\mathrm{D}} \geq 0.6$ will be useful for prediction whilst a difference of more than 0.05 of $R_{\mathrm{D}} \mathrm{s}$ has a substantial importance in prediction. Therefore, $R_{\mathrm{D}}=0.248$ for the best model of all the exotic insects tells us that the 


\section{(a) null model}

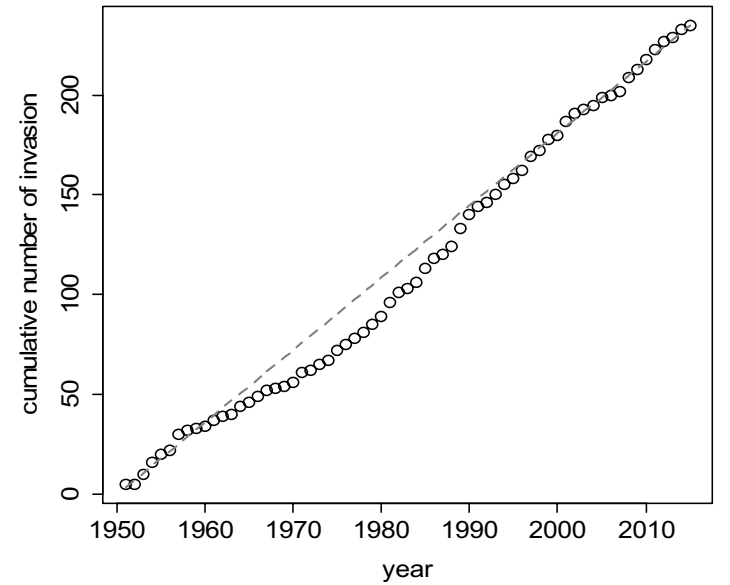

(c) cereals with saturation

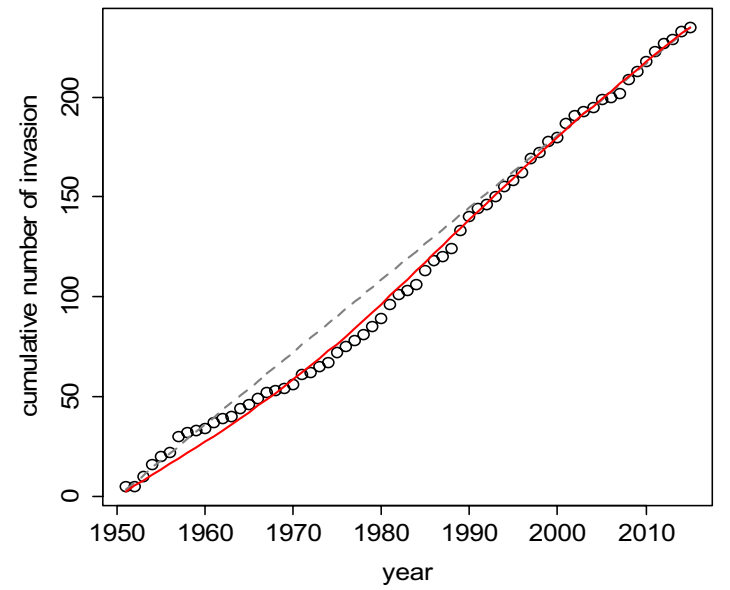

Fig. 3 Annual changes in cumulative discoveries of all the exotic insect pests. a Null model (Model-1) with the constant risk of inflow. b Model-2 with cereals. c Model-3 with cereals and the effect of saturation. $\mathbf{d}$ The best model, Model-4 with cereals, timbers and the effect

model is blunt about prediction but still captures some meaningful structures causing the invasion events. Because the $R_{\mathrm{D}} \mathrm{S}$ of the models, which have the sole effect only of cereals or timbers, did not differ greatly from the best model, we suspect that either cereals or timbers had the same effect, i.e. increasing trends of imports from the 1950 s to the early 1970 s were important for the invasion events. Conversely, the best three models have had lag time and had greater $R_{\mathrm{D}} \mathrm{S}$ than those without lag time (Table 3 ). In addition, the mean lag time between actual invasion and detection is estimated as $1 / \pi=1.8-11.9$ and is well in accordance with the precedent works of Kiritani and Yamamura (2003). The presence of a lag time was ubiquitous in exotic insect records in Japan.

To view the general feature of our four models of all exotic insects, we also plotted the predictions of the null model (Model-1, Fig. 3a), the basic commodity model

\section{(b) cereal}

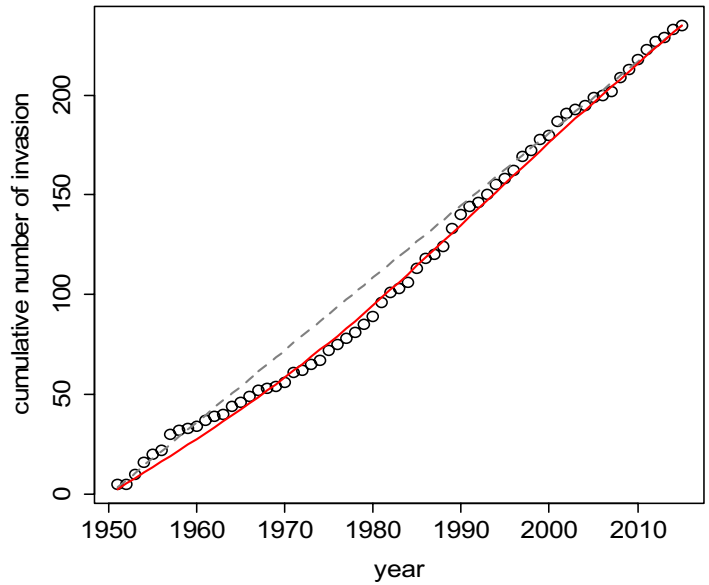

(d) cereals+timbers with lag

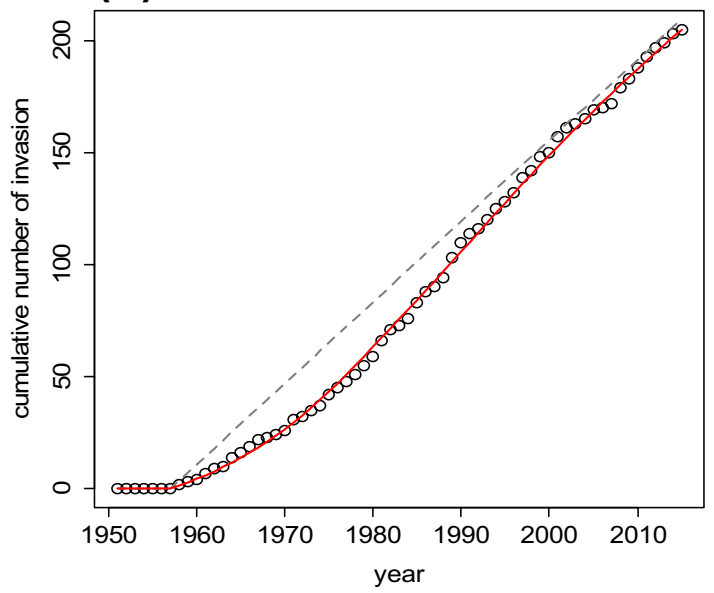

of lag time. Dots are the actual invasion events in the records. Dashed lines are the predictions by the null model (Model-1), and solid lines are the predictions by each model

(Model-2, Fig. 3b) and the commodity with saturation model (Model-3, Fig. 3c) in addition to the best model with lag time (Model-4, Fig. 3d) along with the actual cumulative numbers of invasions over the years. The structure of the lag time typically produced a concave shape in the early decades of the cumulative numbers of invasions (Fig. 3d). The basic commodity model of cereals also had a slightly concave shape but was not so conspicuous as that of the model with lag time (Fig. 3b). This is because imports of cereals steadily increased in the 1960s and the 1970s and then slowed down (Fig. 2d). It should be noted that a function with saturation effect generally had a convex shape along the years (as can be seen in Fig. 4b for Stored pests), whilst the convexity of the model with saturation for all the exotic insects was not prominent (Fig. 3c). This is because the saturation parameter 
Table 3 The best five models for each pest type

\begin{tabular}{|c|c|c|c|}
\hline Model type & $R_{\mathrm{D}}$ & Model structure & $1 / \pi$ \\
\hline \multicolumn{4}{|l|}{ All exotic } \\
\hline 1. Lag & 0.248 & $Y_{t} \sim \operatorname{Poisson}\left[\lambda_{\mathrm{t}}=\exp \left(1.2+0.27 \times\right.\right.$ cereals $_{t}+0.11 \times$ timbers $\left.\left._{t}\right)\right]$ & 4.0 \\
\hline 2. Lag & 0.241 & $Y_{t} \sim \operatorname{Poisson}\left[\lambda_{t}=\exp \left(1.3+0.23 \times\right.\right.$ timbers $\left.\left._{t}\right)\right]$ & 11.9 \\
\hline 3. Lag & 0.237 & $Y_{t} \sim \operatorname{Poisson}\left[\lambda_{t}=\exp \left(1.2+0.34 \times\right.\right.$ cereals $\left.\left._{t}\right)\right]$ & 1.8 \\
\hline 4. Saturation & 0.070 & $Y_{t} \sim$ Poisson $\left[\lambda_{t}=\exp \left(1.5+0.21 \times\right.\right.$ cereals $\left.\left._{t}-0.001 \sum_{j=1951}^{t-1} Y_{j}\right)\right]$ & $\mathrm{NA}^{\mathrm{a}}$ \\
\hline 5. Basic & 0.060 & $Y_{t} \sim \operatorname{Poisson}\left[\lambda_{t}=\exp \left(1.3+0.15 \times\right.\right.$ cereals $\left.\left._{t}\right)\right]$ & NA \\
\hline \multicolumn{4}{|l|}{ Outdoor pests } \\
\hline 1. Saturation $+\mathrm{Lag}^{\mathrm{b}}$ & 0.094 & $Y_{t} \sim$ Poisson $\left[\lambda_{t}=\exp \left(0.55+0.49 \times\right.\right.$ cereals $\left.\left._{t}-0.007 \sum_{j=1951}^{t-1} N_{j}\right)\right]$ & 4.4 \\
\hline 2. Saturation & 0.088 & $Y_{t} \sim$ Poisson $\left[\lambda_{t}=\exp \left(3.2+0.58 \times\right.\right.$ flowers $_{t}+0.66 \times$ cereals $\left._{t}-0.041 \sum_{j=1951}^{t-1} Y_{j}\right)$ & NA \\
\hline 3. Lag & 0.083 & $Y_{t} \sim \operatorname{Poisson}\left[\lambda_{t}=\exp \left(0.19+0.23 \times\right.\right.$ timbers $\left.\left._{t}\right)\right]$ & 15.5 \\
\hline 4. Lag & 0.071 & $Y_{t} \sim \operatorname{Poisson}\left[\lambda_{t}=\exp (0.38)\right]$ & 23.2 \\
\hline 5. Saturation & 0.065 & $Y_{t} \sim$ Poisson $\left[\lambda_{t}=\exp \left(2.6+0.34 \times\right.\right.$ flowers $_{t}+0.63 \times$ fruits $\left.\left._{t}-0.033 \sum_{j=1951}^{t-1} Y_{j}\right)\right]$ & NA \\
\hline
\end{tabular}

Stored pests

1. Saturation

0.261

$Y_{t} \sim$ Poisson $\left[\lambda_{t}=\exp \left(4.8+0.24 \times\right.\right.$ flowers $_{t}+0.49 \times$ cereals $\left.\left._{t}-0.097 \sum_{j=1951}^{t-1} Y_{j}\right)\right]$

NA

2. Saturation

0.261

$Y_{t} \sim$ Poisson $\left[\lambda_{t}=\exp \left(4.7+0.48 \cdot\right.\right.$ cereal $\left.\left._{t}-0.096 \sum_{j=1951}^{t-1} Y_{j}\right)\right]$

3. Saturation

0.245

$Y_{t} \sim$ Poisson $\left[\lambda_{t}=\exp \left(2.7+0.031 \cdot\right.\right.$ timbers $\left.\left._{t}-0.060 \sum_{j=1951}^{t-1} Y_{j}\right)\right]$

NA

4. Saturation

0.245

$Y_{t} \sim$ Poisson $\left[\lambda_{t}=\exp \left(2.6+0.059 \sum_{j=1951}^{t-1} Y_{j}\right)\right]$

5. Saturation + Lag

0.085

$$
Y_{t} \sim \text { Poisson }\left[\lambda_{t}=\exp \left(\begin{array}{c}
19.0+1.2 \times \text { flowers }_{t}+2.1 \times \text { vegs }_{t}+2.5 \times \text { timbers }_{t} \\
-0.39 \sum_{j=1951}^{t-1} N_{j}
\end{array}\right)\right]
$$

NA

Greenhouse pests

1. Saturation + Lag

0.168

$$
Y_{t} \sim \text { Poisson }\left[\lambda_{t}=\exp \left(\begin{array}{c}
21.0+3.4 \times \text { flowers }_{t}+0.67 \times \text { vegs }_{t}+2.6 \times \text { cereals }_{t} \\
+0.21 \times \text { timbers }_{t}-0.39 \sum_{j=1951}^{t-1} N_{j}
\end{array}\right)\right]
$$

2. Saturation + Lag

0.162

$$
Y_{t} \sim \text { Poisson }\left[\lambda_{t}=\exp \left(\begin{array}{c}
19.0+3.2 \times \text { flowers }_{t}+0.87 \times \text { fruits }_{t}+2.2 \times \text { cereals }_{t} \\
-0.40 \sum_{j=1951}^{t-1} N_{j}
\end{array}\right)\right]
$$

3. Saturation + Lag

0.158

$$
Y_{t} \sim \text { Poisson }\left[\lambda_{t}=\exp \left(\begin{array}{c}
19.0+2.9 \times \text { flowers }_{t}+0.51 \times \text { vegs }_{t}+2.6 \times \text { cereals }_{t} \\
-0.38 \sum_{j=1951}^{t-1} N_{j}
\end{array}\right)\right]
$$

4. Saturation + Lag

0.144

$$
Y_{t} \sim \text { Poisson }\left[\lambda_{t}=\exp \left(\begin{array}{c}
11.0+1.7 \times \text { flowers }_{t}+0.69 \times \text { fruits }_{t}+0.21 \times \text { vegs }_{t} \\
+1.2 \times \text { cereals }_{t}-0.23 \sum_{j=1951}^{t-1} N_{j}
\end{array}\right)\right]
$$

5. Saturation

0.110

$$
Y_{t} \sim \text { Poisson }\left[\lambda_{t}=\exp \left(\begin{array}{c}
10.0+1.7 \times \text { flowers }_{t}+0.65 \times \text { fruits }_{t}+1.2 \times \text { cereals }_{t} \\
-0.021 \sum_{j=1951}^{t-1} Y_{j}
\end{array}\right)\right]
$$

NA 
Table 3 (continued)

\begin{tabular}{|c|c|c|c|c|}
\hline Model type & $R_{\mathrm{D}}$ & Model structure & & $1 / \pi$ \\
\hline \multicolumn{5}{|l|}{ Forest pests } \\
\hline 1. Saturation + Lag & 0.205 & $Y_{t} \sim$ Poisson $\left[\lambda_{t}=\exp (\right.$ & $\begin{array}{c}18.0+3.9 \times \text { flowers }_{t}+0.31 \times \text { vegs }_{t}+1.2 \times \text { cereals }_{t} \\
-0.49 \sum_{j=1951}^{t-1} N_{j}\end{array}$ & 1.9 \\
\hline 2. Saturation + Lag & 0.201 & $Y_{t} \sim$ Poisson $\left[\lambda_{t}=\exp \right.$ & $\left(18.0+4.2 \times\right.$ flowers $_{t}+1.3 \times$ cereals $_{t}-0.50 \sum_{j=1951}^{t-1} N_{j}$ & 1.7 \\
\hline 3. Saturation & 0.190 & $Y_{t} \sim$ Poisson $\left[\lambda_{t}=\exp (\right.$ & $\begin{array}{c}13.0+3.2 \times \text { flowers }_{t}+0.071 \times \text { vegs }_{t}+0.99 \times \text { cereal } \\
-0.37 \sum_{j=1951}^{t-1} Y_{j}\end{array}$ & NA \\
\hline 4. Saturation & 0.190 & $Y_{t} \sim$ Poisson $\left[\lambda_{t}=\exp \right.$ & $\left(13.0+3.3 \times\right.$ flowers $_{t}+1.0 \times$ cereals $_{t}-0.38 \sum_{j=1951}^{t-1} Y_{j}$ & NA \\
\hline 5. Saturation + Lag & 0.168 & $Y_{t} \sim$ Poisson $\left[\lambda_{t}=\exp (\right.$ & $\begin{array}{c}18.0+0.026 \times \text { flowers }_{t}+0.60 \times \text { fruits }_{t}+4.0 \times \text { vegs }_{t} \\
-0.51 \sum_{j=1951}^{t-1} N_{j}\end{array}$ & 11.1 \\
\hline \multicolumn{5}{|l|}{ Timber pests } \\
\hline 1. Saturation + Lag & 0.189 & $Y_{t} \sim$ Poisson $\left[\lambda_{t}=\exp (\right.$ & $\begin{array}{c}\left.15.0+2.8 \times \text { flowers }_{t}+0.36 \times \text { vegs }_{t}+4.5 \times \text { cereals }_{t}\right) \\
-2.1 \sum_{j=1951}^{t-1} N_{j}\end{array}$ & 1.6 \\
\hline 2. Saturation $+\mathrm{Lag}$ & 0.186 & $Y_{t} \sim$ Poisson $\left[\lambda_{t}=\exp \right.$ & $\left(14.0+2.9 \times\right.$ flowers $_{t}+4.4 \times$ cereals $\left._{t}-2.0 \sum_{j=1951}^{t-1} N_{j}\right)$ & 1.6 \\
\hline 3. Saturation & 0.174 & $Y_{t} \sim$ Poisson $\left[\lambda_{t}=\exp (\right.$ & $\begin{array}{c}12.0+2.1 \times \text { flowers }_{t}+0.43 \times \text { vegs }_{t}+4.0 \times \text { cereals }_{t} \\
-1.7 \sum_{j=1951}^{t-1} Y_{u}\end{array}$ & NA \\
\hline 4. Saturation & 0.169 & $Y_{t} \sim$ Poisson $\left[\lambda_{t}=\exp \right.$ & $\left(12.0+2.3 \cdot\right.$ flowers $_{t}+4.0 \cdot$ cereals $\left._{t}-1.7 \sum_{u=1951}^{t-1} Y_{u}\right)$ & NA \\
\hline 5. Saturation & 0.132 & $Y_{t} \sim$ Poisson $\left[\lambda_{t}=\exp (\right.$ & $\left.\begin{array}{c}6.6+0.30 \times \text { flowers }_{t}+1.0 \times \text { vegs }_{t}+2.3 \times \text { cereals }_{t} \\
-1.1 \sum_{u=1951}^{t-1} Y_{u}\end{array}\right]$ & NA \\
\hline
\end{tabular}

aNA is "not available" because the model does not have a lag time structure

${ }^{\mathrm{b}}$ The saturation term of the model with saturation + lag was modelled as the accumulations of the number of detections $\left(N_{j}\right)$ rather than those of the actual numbers of invasions $\left(Y_{j}\right)$

$\gamma$ was small $(\gamma=0.0011)$ and could not make a substantial retardation in the latter part of the periods.

The results of the five exotic agricultural pest insect types are shown in Fig. 4 and Table 3. The best model of Outdoor pests had the effects of saturation and lag time, whilst the $R_{\mathrm{D}}$ was 0.094 , which was larger than 0.05 but was poor for prediction. The saturation and/or lag time were detected in the best five models for each and in combination, and they were not different amongst the models in terms of prediction power, $R_{\mathrm{D}}$. Though the effects of cereals, flowers, timbers, and fruits were estimated, those effects are vague because the $R_{\mathrm{D}} \mathrm{S}$ were not different from the model with lag time and the constant risk of invasion (the fourth best model in Table 3).
The best four models of Stored pests had the effect of saturation and the saturation in Stored pests was visually conspicuous in Fig. 4. On the other hand, the effect of commodity was ambiguous, as the $R_{\mathrm{D}} \mathrm{s}$ were not different from the model with lag time and the constant risk of invasion with saturation (the fourth best model in Table 3). Similar to Stored pests, saturation was detected in Greenhouse, Forest, and Timber pests (Table 3), although the effects were not visually conspicuous in Greenhouse and Forest pests (Fig. 4c, d) as was seen in Stored pests (Fig. 4b). All three pest types had combination effects of flowers, vegs or fruits, cereals. It may be noted that whilst cereals have an increasing trend from 1950 to 1980 , flowers did so after the 1990s and fruits and vegs were somewhat intermediate. Therefore, 
(a) Outdoor pests

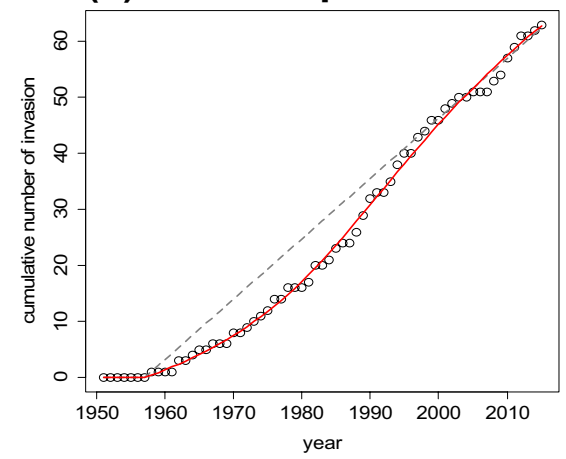

(d) Forest pests

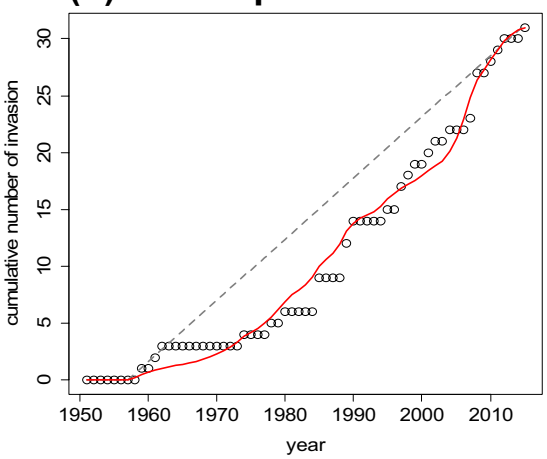

(b) Stored pests

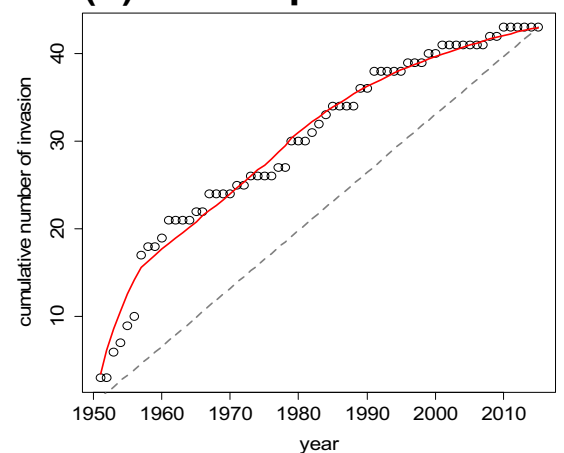

(e) Timber pests

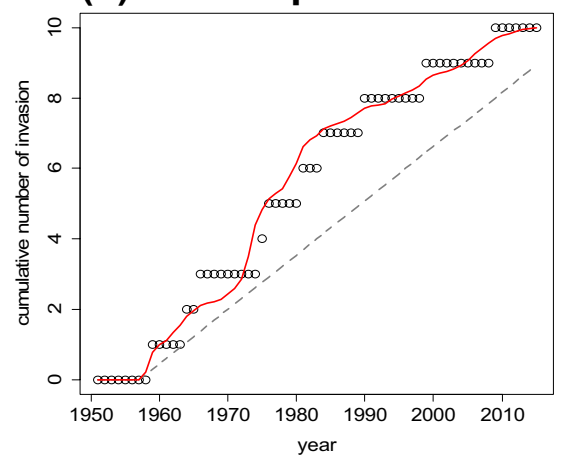

(c) Greenhouse pests

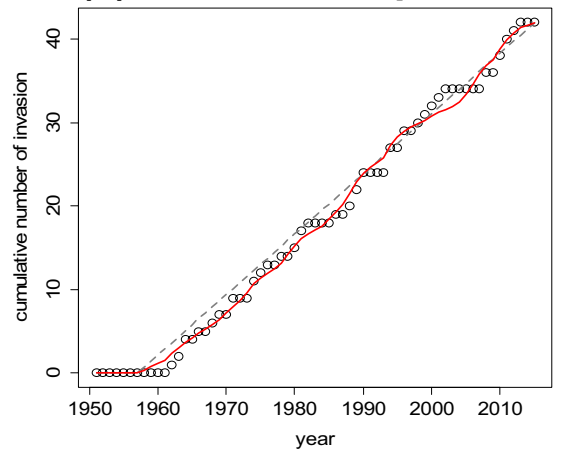

Fig. 4 Annual changes in cumulative discoveries of the five agricultural pest types. a Outdoor pests (Model-5 with cereals and the effect of saturation and lag time). b Stored pests (Model-3 with cereals and the effect of saturation). c Greenhouse pests (Model-5 with flowers, vegs, cereals and timbers and the effects of saturation and lag time). d Forest pests (Model-5 with flowers, vegs, and cereals and the effect of saturation and lag time). e Timber pests (Model-5 with flowers, vegs, and cereals and the effects of saturation and lag time). Dots are the actual invasion events in the records. Dashed lines are the prediction by the null model (Model-1), and solid lines are the prediction by the best model (see text and Table 3 for detail)

find a clear relationship between the invasion records and each commodity type, all the commodities had significant impacts on the invasion of some or all insect types (Table 3). Our findings will have a great impact on the invasion ecology and biosecurity policies because we need to monitor all the agricultural imports, as has been the case in the past. In addition, we must assume that there are hidden establishments of some invasive alien insects other than those we have already found. Some unrecognised species, which are harmless today, may become the invasive pest of tomorrow under climate change. It may be possible to concentrate our quarantine efforts on those pests with lesser saturation effects than those already being saturated.

It is worth emphasising that the lag time was selected in all five best models in the analyses of all the exotic insects, whilst saturation was detected in all the best five models of all the agricultural pest types, except for the null models (Table 3). The reason why lag time was not always detected in each agricultural pest type reflects the reduction of statistical power in each fragmented dataset volume in each pest type. In addition, this could be caused by the variation in detectability of each pest type, i.e. some pest types are easier of the five agricultural pest types. Although we could not 
to be detected than others. On the other hand, the reason why we could not find the saturation on the invasion records of all the exotic insects was from the result of admixture amongst those having different saturation patterns in each pest type. For example, saturation is prominent in Stored pests as can be seen in Fig. 4b and it was observed just after the 1950s. Stored pests comprise many cosmopolitan insect pests which might have already been widespread across the world in the 1950s [e.g. cockroaches (Blattodea), Tribolium confusum Jacquelin du Val (Coleoptera: Tenebrionidae), Alphitobius species (Coleoptera: Tenebrionidae), Trogoderma inclusum LeConte (Coleoptera: Dermestidae) and Ephestia kuehniella (Zeller) (Lepidoptera: Pyralidae)]. They came into Japan with food aid (mainly wheat grain) from North America after World War II. They could have easily settled down in the newly built up mills in the 1950s in Japan (Kiritani 1959; Kiritani et al. 1963). On the other hand, Outdoor, Greenhouse, and Forest pests were constantly invading or were accelerated after the 1970s compared to Stored pests. Many Timber pests (e.g. bark beetles such as Minthea rugicollis (Walker) (Coleoptera: Bostrichidae) and Lyctus carbonarius Waltl (Coleoptera: Bostrichidae), and the termite Incisitermes minor (Hagen) (Blattodea: Kalotermitidae)) arrived in Japan from the 1960s to the 1970s, and their saturation took place after the 1970s (Fig. 4e). Greenhouse pests (e.g. Trialeurodes vaporariorum (Westwood) (Hemiptera: Aleyrodidae), Frankliniella occidentalis (Pergande) (Thysanoptera: Thripidae), and Liriomyza trifolii (Burgess) (Diptera: Agromyzidae)) became serious pests after the 1970s when greenhouse farming became popular in Japan, although saturation was hardly observed in Fig. 4c (Kiritani and Morimoto 2004; Morimoto 2010).

Contrary to our analyses, Seebens et al. (2017) concluded that there were no signs of saturation in any taxonomic group when they merged all the world records of exotic species. We suspect that they could not find saturation because different pathways (commodities) and different phagus types of exotic species were integrated in their analyses. In fact, we could not find a substantial effect of saturation when we integrated all the exotic insects into one group (Table 3). World trades always exploit new commodities from new regions year after year; such trends mask the saturation which could have been found when the records were divided by commodity and pest types.

Lag time between the actual timing of invasion and discovery has also been recognised in invasion ecology for many years (Kowarik 1995; Mack et al. 2000; Sakai et al. 2001). Exotic insects need time to overcome the founder effects and become naturalised in a new environment (Crooks and Soulé 1999; Lockwood et al. 2005). Kiritani and Yamamura (2003) did an intensive survey for scientific reports in Japan and concluded that many invasive insects generally have a lag time of 4-10 years before their detection. In addition, the lag time can also be owing to ineffective surveillance, which can be caused by the limitation of time and efforts and by imperfect taxonomic detectability (Berec et al. 2014; Epanchin-Niell et al. 2012). The gypsy moth in North America took more than 20 years to expand their population beyond $500 \mathrm{~m}$, whilst now they are aggressively expanding at a rate of $21 \mathrm{~km} /$ year (Liebhold and Tobin 2006). However, the gypsy moth invasion in North America is a rare exception; since people knew accurately where they were released and how they have expanded since 1869 . Moreover, the latent period further increases with increasing heterogeneity in the destination environment (Yamamura 2002; Yamamura et al. 2007).

Though the lag time was not so prominent compared to the effect of saturation, there are several models selected in our analyses with lag time structures for some agricultural pest types. The mean expectation of lag time can be calculated as $1 / \pi$ and the topology of the likelihood function of $\pi$ is nearly flat from $\pi=0$ to $\pi=1.0$ (Berger et al. 1999). Therefore, we cannot heavily rely on a single estimation of $1 / \pi$. Nonetheless, insects classified as Outdoor pests had slightly longer lag time (4.4-23.2 years) than did those marked as Greenhouse pests (1.5-2.1 years). Though the long lag time in Outdoor pests is ambiguous because of the uncertainty in $1 / \pi$, it may reflect a piece of evidence: unfamiliar insect pests can be identified more easily in the greenhouse than outdoors. We could not find a lag time in the first to fourth best models of Stored pests; we hypothesise that this is because Kiritani (1959) and Kiritani et al. (1963) intensively surveyed the mills with enough knowledge of stored product pests and listed the detailed records of pest insects just after the mills were built.

We used $R_{\mathrm{D}}$ in evaluating the predictive ability of models. $R_{\mathrm{D}}$ enables us to evaluate the goodness of models whilst other criteria such as AIC enable only the selection of the best model. Notice that the best model is not always a good model. In our results of analyses shown in Table 3, the 'Saturation + Lag' model was the best model for Outdoor pests whilst the 'Saturation' model was the best model for Stored pests. The $R_{\mathrm{D}} \mathrm{s}$ are much different between the two models: 0.094 and 0.261 , respectively. This indicates that the best model for Outdoor pests is not a good model for prediction. The invasion of Outdoor pests may be highly influenced by other explanatory variables such as outdoor environmental conditions that were not included in our current models.

Regrettably, we could not find any clear connection between the specific commodity types and agricultural pest types. Recently, Chapman et al. (2017) found that the recent invasion of exotic species is more connected to live plant imports than to the other commodities and socio-economic factors in European and Mediterranean countries. Liebhold et al. (2012) also reported that $70 \%$ of invasive forest pests in the United States are likely imported with live plants. In our 
analyses, although flowers were estimated as an important factor, cereals, timbers and vegs also had similar importance in many model candidates of all the pest types. This ambiguity may stem from our data quality. The year of discovery inevitably contained uncertainty and variations amongst surveys, whilst we only had 235 exotic species for which we found the record of the first year of detection. In addition, the lag time tweaks the direct relationship between the commodity and invasion events, as was assumed in our analyses. Moreover, the lag time itself contains uncertainty. The establishment probability must be different amongst pest insects even though the chances of invasion with commodity do affect it according to Brockerhoff et al. (2014). In future research, we plan to incorporate the interception records of air and seaports, in addition to the establishment records, into our analyses. Hopefully, the interception records will help to obtain the propagule pressure with the commodity and establishment rate, which also correspond to the pest biology.

Acknowledgements We would like to thank Ms. K. Murata for her assistance in compiling records, and the anonymous reviewers for providing us with their thoughtful comments on the earlier version of our manuscript.

Conflict of interest The authors declare that they have no conflict of interest.

Open Access This article is distributed under the terms of the Creative Commons Attribution 4.0 International License (http://creativeco mmons.org/licenses/by/4.0/), which permits unrestricted use, distribution, and reproduction in any medium, provided you give appropriate credit to the original author(s) and the source, provide a link to the Creative Commons license, and indicate if changes were made.

\section{References}

Akaike H (1974) A new look at the statistical model identification. IEEE Trans Autom Constr AC-19:716-723. https://doi. org/10.1109/TAC.1974.1100705

Aukema JE, McCullough DG, Holle BV, Liebhold AM, Britton K, Frankel SJ (2010) Historical accumulation of non-indigenous forest pests in the continental US. Bioscience 60:886-897. https:// doi.org/10.1525/bio.2010.60.11.5

Berec L, Kean JM, Epanchin-Niell R, Liebhold AM, Haight RG (2014) Designing efficient surveys: spatial arrangement of sample points for detection of invasive species. Biol Invasions 17:445-459. https ://doi.org/10.1007/s10530-014-0742-x

Berger JO, Liseo B, Wolpert RL (1999) Integrated likelihood methods for eliminating nuisance parameters. Stat Sci 14:1-28. https://doi. org/10.1007/s10530-014-0742-x

Brockerhoff EG, Kimberley M, Liebhold AM, Haack RA, Cavey JF (2014) Predicting how altering propagule pressure changes establishment rates of biological invaders across species pools. Ecology 95:594-601. https://doi.org/10.1890/13-0465.1

Burnham KP, Anderson DR (2014) $P$ values are only an index to evidence: 20 th- vs. 21 st-century statistical science. Ecology 95:627630. https://doi.org/10.1890/13-1066.1
Chambers JM, Hastie TJ (1993) Statistical models in S. Chapman \& Hall Computer Science Series. Chapman \& Hall, London

Chapman D, Purse BV, Roy HE, Bullock JM (2017) Global trade networks determine the distribution of invasive non-native species. Glob Ecol Biogeogr 26:907-917. https://doi.org/10.1111/ geb.12599

Costello C, Springborn M, McAusland C, Solow A (2007) Unintended biological invasions: does risk vary by trading partner? J Environ Econ Manag 54:262-276. https://doi.org/10.1016/j. jeem.2007.06.001

Crooks JA, Soulé ME (1999) Lag times in population explosions of invasive species: causes and implications. In: Sandlund OT, Schei PJ, Viken A (eds) Invasive species and biodiversity management, proceedings, Norway/UN Conference on Alien species, directorate for nature management and Norwegian Institute for Nature, pp 39-46

Epanchin-Niell RS, Haight RG, Berec L, Kean JM, Liebhold AM (2012) Optimal surveillance and eradication of invasive species in heterogeneous landscapes. Ecol Lett 15:803-812. https://doi. org/10.1111/j.1461-0248.2012.01800.x

Garnas JR, Auger-Rozenberg M-A, Roques A et al (2016) Complex patterns of global spread in invasive insects: eco-evolutionary and management consequences. Biol Invasions 18:935-952. https://doi.org/10.1007/s10530-016-1082-9

Kiritani K (1959) Problems in the stored product entomology. Osaka Plant Prot 7:1-44 (in Japanese)

Kiritani K (2004) Agriculture considering neutral arthropods (Tadano mushi wo mushi shinai nougyou). Tsukiji-Shokan, Tokyo (in Japanese)

Kiritani K, Morimoto N (2004) Invasive insect and nematode pests from north America. Glob Environ Res 8:7-88

Kiritani K, Yamamura K (2003) Exotic insects and their pathways for invasion. In: Ruiz GM, Carlton JT (eds) Invasive species-vectors and management strategies. Island Press, Washington, pp 44-67

Kiritani K, Muramatsu T, Yoshimura S (1963) Characteristics of mills in faunal composition of stored product pests: their role as a reservoir of new imported pests. Jpn J Appl Entomol Zool 7:49-58

Kowarik I (1995) Time lags in biological invasions with regard to the success and failure of alien species. In: Paper presented at the Plant invasions: general aspects and special problems. Workshop held at Kostelec nad Černými lesy, Czech Republic, 16-19 September 1993

Levine JM, D'Antonio CM (2003) Forecasting biological invasions with increasing international trade. Conserv Biol 17:322-326. https://doi.org/10.1046/j.1523-1739.2003.02038.x

Liebhold AM, Tobin PC (2006) Growth of newly established alien populations: comparison of North American gypsy moth colonies with invasion theory. Popul Ecol 48:253-262. https://doi. org/10.1007/s10144-006-0014-4

Liebhold AM, Brockerhoff EG, Garrett LJ, Parke JL, Britton KO (2012) Live plant imports: the major pathway for forest insect and pathogen invasions of the US. Front Ecol Environ 10:135-143. https://doi.org/10.1890/110198

Lockwood JL, Cassey P, Blackburn TM (2005) The role of propagule pressure in explaining species invasions. Trends Ecol Evol 20:223-228. https://doi.org/10.1016/j.tree.2005.02.004

Mack RN, Simberloff D, Lonsdale WM, Evans H, Clout M, Bazzaz FA (2000) Biotic invasions: causes, epidemiology, global consequences, and control. Ecol Appl 10:689-710

Ministry of Finance (1951-2018) Trade of Japan, Japan Tariff Association, Tokyo (in Japanese)

Morimoto N (2010) Effect of global warming on the biological invasion of arthropod pests. Shokubutsu-boeki (Plant protection) 64:443-447 (in Japanese)

Sailer RI (1978) Our immigrant insect fauna. ESA Bull 24:3-11 
Sakai AK, Allendorf FW, Holt JS et al (2001) The population biology of invasive species. Ann Rev Ecol Syst 32:305-332. https://doi. org/10.1146/annurev.ecolsys.32.081501.114037

Seebens H, Blackburn TM, Dyer EE et al (2017) No saturation in the accumulation of alien species worldwide. Nat Commun 8:14435. https://doi.org/10.1038/ncomms14435

The Japanese Society of Applied Entomology and Zoology (2006) Major insect and other pests of economic plants in Japan. Japan Plant Protection Association, Tokyo (in Japanese)

Yamamura K (2002) Dispersal distance of heterogeneous populations. Popul Ecol 44:93-101. https://doi.org/10.1007/s101440200011

Yamamura K (2016) Estimation of the predictive ability of ecological models. Commun Stat Simul Comput 45:2122-2144. https://doi. org/10.1080/03610918.2014.889161
Yamamura K, Moriya S, Tanaka K, Shimizu T (2007) Estimation of the potential speed of range expansion of an introduced species: characteristics and applicability of the gamma model. Popul Ecol 49:51-62. https://doi.org/10.1007/s10144-006-0001-9

Yamanaka T, Morimoto N, Nishida GM, Kiritani K, Moriya S, Liebhold AM (2015) Comparison of insect invasions in North America, Japan and their Islands. Biol Invasions 17:3049-3061. https ://doi.org/10.1007/s10530-015-0935-y

Publisher's Note Springer Nature remains neutral with regard to jurisdictional claims in published maps and institutional affiliations. 